\title{
Recommendations for standardized oral toxicity test protocols for larvae of solitary bees, Osmia spp.
}

\author{
Maxime Eeraerts, Matti Pisman, Ruben Vanderhaegen, Ivan Meeus, Guy Smagghe \\ Department of Plant and Crops, Faculty of Bioscience Engineering, Ghent University, Coupure Links, 653, Ghent, \\ Belgium
}

Received 4 June 2019 - Revised 10 September 2019 - Accepted 9 October 2019

\begin{abstract}
Effects of pesticides have been debated as one of the causes of worldwide declines of bee populations. Improving the risk assessment of pesticides on bees is important to halt these declines. Pesticide risk assessment today mainly focuses on one bee species, the honey bee. Because of differences in life cycles among bee species, this risk assessment needs to be adapted to take these differences into account. For both the adult and larval life stages, development of test protocols for solitary bees is required. Here, we summarize the current knowledge on larval tier 1 tests based on the first test protocols for solitary bee larvae available in the literature. As the ecology and rearing of solitary bees of the genus Osmia spp. are well known, we propose this genus as a model species in a first step to develop protocols for solitary species. In addition, we discuss guidelines, relevant endpoints, and research needs for the development of a standardized oral toxicity test protocol of solitary bee larvae.
\end{abstract}

pesticides / solitary bees / Osmia spp. / oral toxicity test / ecotoxicology

\section{INTRODUCTION}

The pollination service of bees contributes significantly to agriculture and natural ecosystems (Ollerton et al. 2011; Garibaldi et al. 2013). Unfortunately, wild bee populations have declined over the last decades (Biesmeijer et al. 2006; Carvalheiro et al. 2013; Powney et al. 2019). The use of pesticides in agriculture has been attributed as one of the underlying causes of those declines (Goulson et al. 2015; Woodcock et al. 2017). Indeed, widespread application of pesticides results in contamination of nectar and pollen in flowering plants through which different developmental stages of bees can be exposed to pesti-

Corresponding author: M. Eeraerts, maxime.eeraerts@ugent.be Handling Editor: Monique Gauthier cides (Botias et al. 2015; David et al. 2016; Wood and Goulson 2017).

Pesticide risk assessment today mainly focuses on one bee species, the honey bee (Apis mellifera), while non-Apis pollinator groups such as bumble bees and solitary bees are heavily underrepresented in risk assessment studies (EFSA 2013). To account for non-Apis pollinators in risk assessments, attempts have been made to extrapolate honey bee toxicity data to bumble bee species and solitary bee species (Arena and Sgolastra 2014; Uhl et al. 2016; Heard et al. 2017). Yet, these predictions only account for effects on adult worker bees and they do not account for differences in nesting biology and annual life cycles between honey bees and other bee species (Thompson 2016; Stoner 2016). Recently, standardized tier I acute toxicity test protocols have been developed for adult worker bumble bees by the non-Apis working group from the International Commission for Plant-Pollinator Relationships 
(OECD 2017a, b). However, just like honey bees, bumble bees are social insects and life cycles and relevant life history traits for risk assessment of social bees differ from solitary bees in many aspects (Sgolastra et al. 2018a; Kopit and PittsSinger 2018). For example, most social bee species continuously feed their larvae and brood care is provided by the worker bees, whereas larvae of solitary bees are only provided with a single food provision after which interaction with the mother bee stops. As such, the death of an adult solitary bee also leads to a complete stop of her reproductive output, whereas the death of a social worker bee can potentially be buffered by the work of her sister worker bees (Straub et al. 2015). In addition, due to differences in life cycles and life history traits, the routes through which social and solitary bees (during all life stages) are exposed to pesticides are different (Sgolastra et al. 2018a). Given these differences in life cycles and exposure routes between social bees and solitary bees, present toxicity protocols are not representative nor applicable for solitary bee species, which encompass the majority of all known bee species (Michener 2007). Therefore, updated toxicity test protocols are crucial to determine potential effects and assess the risks of pesticides on solitary bee species. With robust, standardized test protocols, the relative sensitivity between different species can then be tested and included in risk assessment (Thompson and Pamminger 2019).

Examples of tier 1 toxicity studies exist for adult solitary bee species of the genus Megachile spp. (Johansen et al. 1984; Huntzinger et al. 2008; Scott-Dupree et al. 2009) and Osmia spp. (Ladurner et al. 2005; Scott-Dupree et al. 2009; Biddinger et al. 2013; Jin et al. 2015; Sgolastra et al. 2017, 2018b). However, tier 1 toxicity protocols using adult solitary bees are only able to assess effects on adult survival. Potential effects on survival and development from the egg to the larval stage until the emergence of an adult bee cannot be assessed using these protocols, while significant exposure to pesticides can occur during this stage. Female solitary bees provide their offspring with unprocessed pollen as the main food source mixed with nectar and specific gland secretions to create a compact pollen provision (Norden 1984; Torchio 1989). As such, larval exposure to pesticides will mainly occur through the provided pollen and nectar during the larval development, when the larvae consume relatively large quantities of contaminated food compared to their body size. Therefore, the larval development is also an important life stage to evaluate the impact of pesticides on solitary bee populations which has received very little attention up until now. In addition, it is also not possible to use the results of studies of honey bees as a proxy for solitary bees. This is because the nesting biology and other life history traits (overlapping generations, division of reproduction (workers and queens), cooperative brood care, etc.) between the honey bee and solitary bees are very different (Michener 2007). In addition, comparative studies have not been carried out (Thompson and Pamminger 2019).

To date, a few studies have tested the effects of pesticides using solitary bee larvae of the genus Megachilidae spp. (Guirguis and Brindley 1974; Johansen et al. 1984; Peach et al. 1994; Abbott et al. 2008; Gradish et al. 2012; Anderson and Harmon-Threatt 2019) and Osmia spp. (Tesoriero et al. 2003; Abbott et al. 2008; Konrad et al. 2008; Sgolastra et al. 2015; Nicholls et al. 2017; Anderson and Harmon-Threatt 2019). However, differences among the different test protocols and endpoints measured in each study make it difficult to compare results. Further standardization and validation of testing protocols are necessary to identify representative endpoints for both lethal and sublethal effects and develop a reliable toxicity protocol for solitary bee larvae. As solitary bees of the genus Osmia spp. are distributed worldwide and rearing and handling methods are well known, they are a good model species to include in pesticide risk assessment (EFSA 2013; Sgolastra et al. 2018a). Although we stress that results obtained for Osmia spp. may not be fully representative for all solitary bee genera, using this genus as model species can provide a first step in improving toxicity protocols of other solitary bee species. Indeed, except for the harvesting of the larvae, all elements of our protocol guidelines are suitable for strict solitary species that provide their larvae with a single food provision and then allow them to develop in an enclosed space. As such, this protocol could be used as a 
starting point for risk assessment on other solitary bee species once reliable methods for rearing and testing larvae have been developed. Below we summarize the different stages of the development of Osmia spp. larvae from egg to adult bee. We review and list relevant endpoints for risk assessment protocols and propose a standardized protocol for tier 1 risk assessment with larvae from Osmia spp., while highlighting knowledge gaps and potential further research necessary to optimize the proposed protocol.

\section{SPECIES DESCRIPTION AND RELEVANT ENDPOINTS}

The term "solitary bees" encompasses multiple genera, with differences in life cycles and body sizes between and within genera (Michener 2007). The basic principle of collecting pollen in a nest cell to provide one egg with provisions is the same for most solitary species. Other differences in life cycle, nesting ecology, or body size may affect the potential impact of pesticides both on the adult bees as during larval development. Concerning solitary bees, Osmia spp. are relatively easy to propagate in artificial trap nests and a lot of experience exists with a handful of species (O. bicornis and O. cornuta in Europe, O. lignaria in Canada and the USA, $O$. ribifloris in the USA and Mexico, and O. cornifrons in Japan and the USA; see Sgolastra et al. 2018a).

Bees of the genus Osmia spp. are polylectic bees that naturally nest in pre-existing cavities (dead plant stems, cavities in dead wood and stone, etc.) (Krunić and Stanisavljević 2006). Like most solitary bee species, the yearly flight period of Osmia spp. species is much shorter compared to that of honey bees and bumble bees and foraging preferences are very variable among different species. Larvae of Osmia spp. are provided with a single food provision after which the nest cell is closed and all interaction with the mother bee stops. Osmia spp. have five larval instar stages (Rust et al. 1989; Torchio 1989). The first instar larvae remain within the egg and feed on embryonic fluids. From the second instar stage onwards, the larvae emerge and start to consume the provided pollen. The feeding period can last 40-60 days during which the larvae will molt multiple times until the fifth instar stage is reached (Krunić and Stanisavljević 2006). After the larval development is completed, the fifth instar defecates, passes over into the prepupal stage, and starts spinning a cocoon. Inside the cocoon, the prepupa metamorphoses and stays inside the cocoon during winter as a diapausing adult until it emerges next spring (Krunić and Stanisavljević 2006).

To assess toxicological effects of pesticides during larval development, hibernation, and post-emergence life of the adult bees, both lethal and sublethal endpoints need to be considered. Below, we suggest primary and secondary lethal and sublethal endpoints for larval tier 1 risk assessments with Osmia spp. Primary endpoints are those necessary to understand the immediate risks on the individuals and consequently the bee population, whereas the secondary endpoints are used as information for the drivers of this impact which could be assessed in higher tier (semi-field or field) studies (EFSA 2013). Different endpoints and how to assess each endpoint are summarized in Table I.

\subsection{Lethal effects}

During the egg and first instar stage, the progeny will only be exposed to pesticides through direct contact with the pollen provision, as no feeding occurs yet. As such, failing to develop to the second instar stage provides a first endpoint to assess whether or not the pesticide has any lethal effects through contact with the egg or first instar. Contact with pesticides through dipping of eggs in pesticide solutions has shown potential effects through mortality in eggs of other insect species such as ladybugs (Youn et al. 2003; Fogel et al. 2013). One study reported negative effects of an insect growth regulator, novaluron, on egg hatching and larval survival in Megachile rotundata (Hodgson et al. 2011). These results imply that entering the larval feeding stage is a potential endpoint to take into account, while today this is largely overlooked in the present toxicity studies with solitary species.

As soon as the second instar stage is reached, the progeny will mainly be exposed to pesticides through oral consumption of the pollen 
Table I. Overview of suggested endpoints and how to assess each endpoint (primary endpoints are indicated with an asterisk)

Endpoint

How to score endpoint

Development to second instar larva ${ }^{\mathrm{a}}$

Cocoon initiation $^{\mathrm{a}}$

Adult emergence ${ }^{\mathrm{a}, *}$

Time from second instar larva to cocoon initiation $^{\mathrm{b}}$

Deviation emergence date ${ }^{b}$

Adult longevity ${ }^{\mathrm{b}, *}$

Hibernation weight loss ${ }^{b}$

Body size $^{\mathrm{b}}$

Wing symmetry
Daily observation for hatched, feeding larva

Observation of feeding larvae up to the spinning of the first attachment points of the cocoon

Observation for hatched adult bee during emergence incubation

Daily observation during feeding stage of larvae up to cocoon initiation

Comparison of adult emergence date between treatment and control

Daily observation after emergence of adult up to death of the adult bee

Weight difference of cocoon before and after hibernation

Measure anterior wing length

Comparison of wing shape

${ }^{\mathrm{a}}$ Lethal endpoint

${ }^{\mathrm{b}}$ Sublethal endpoint

provisions. Therefore, from this instar stage onwards, toxic effects should mainly be considered as a consequence of oral exposure. Once the pollen provision has been consumed and larval development is completed, the prepupa will spin a cocoon and develop into an adult bee. Reaching the point of cocoon initiation is a second endpoint to consider as it detects potential lethal effects through oral consumption during larval development. Reaching the point of cocoon initiation has been found to be affected by field realistic doses of insecticides in a larval toxicity test with M. rotundata (Gradish et al. 2012).

Once the cocoon has been successfully spun, bees will pupate and from here on enter hibernation as a fully developed adult bee and wait for the next spring to emerge (Bosch and Kemp 2000; Kemp et al. 2004). Successful emergence of the adult bee from the cocoon after hibernation is the third potential endpoint for lethal effects, as accumulated residues in the bee might reduce the fitness and consequently the survival rate during hibernation. Effects of pesticides on mortality during hibernation were not found for M. rotundata (Gradish et al. 2012) or Osmia spp. (Konrad et al. 2008; Nicholls et al. 2017). However, in a semi-field test, Sandrock et al. (2014) detected significant effects of neonicotinoid insecticides on adult emergence of
O. bicornis. Successful emergence of the adult bee is a first primary endpoint as it clearly indicates risks concerning the larval development and consequent fitness of the adult bee.

\subsection{Sublethal effects}

During larval development, the first sublethal endpoint to consider is the duration to develop from second instar to cocoon spinning initiation. Pesticide treatments may potentially slow down larval development, leading to potential delays in reaching the fully developed larval stage. Delayed larval development may impose higher risks of development failure due to prolonged exposure to pathogenic infections, parasitism, or adverse weather conditions. Such a delayed larval development by pesticides has already been detected for honey bee larvae (Wu et al. 2011; Vázquez et al. 2018). Effects of imidacloprid on larval development time of $M$. rotundata also have been detected (Anderson and Harmon-Threatt 2019). Konrad et al. (2008) also found prolonged larval development in the presence of the lectin Galanthus nivalis agglutinin (GNA) in O. bicornis, again stressing the relevance of this endpoint.

After larval development, the cocoons are subjected to a winter incubation to simulate diapause 
and to stimulate adult emergence. Once bees have successfully emerged from their cocoon, several additional endpoints can be assessed on the adult bees to detect potential sublethal effects from pesticide treatments. A first endpoint here is the deviation of the emergence date compared to a negative control group. Timing of emergence can play a large role in fitness for both male and female individuals with regard to mismatches with floral resources and mating opportunities (Forrest and Thomson 2011; Schenk et al. 2018a, b). However, no data is available on how pesticide exposure could shift timing of emergence (but see Sgolastra et al. 2015). Assessing the longevity in the absence of food is another potential endpoint for sublethal effects. Pesticide residue uptake during the larval stage can potentially reduce the longevity of adult bees after emergence (Wu et al. 2011; Sgolastra et al. 2015). Survival without food is recommended as endpoint as it gives an estimate of the bees' survival chances in natural conditions with uncertainty of food sources. Especially for early spring species, prolonged rainfall and too cold temperatures can keep a solitary bee stuck in their nest for multiple days. Bees with a lower longevity will be more susceptible to fluctuations in food resource availability and are likely to have a reduced fitness in such conditions (Sgolastra et al. 2011; Weissel et al. 2012). Therefore, longevity of the emerged adult is the second primary endpoint.

Disturbances in development of the individual bees are a final group of endpoints to consider. These endpoints include weight loss during hibernation, body size, and wing symmetry. Cocoon weight can be measured before and after hibernation, to assess weight loss during hibernation. Significant weight loss during hibernation indicates energy loss in winter and reduced vitality of the bees (Bosch and Kemp 2004). Therefore, weight loss during hibernation can be very useful to associate with adult emergence and adult longevity. In bumble bee queens, weight loss during hibernation has been found to be greater for individuals exposed to neonicotinoids (Fauser et al. 2017). However, Konrad et al. (2008) found no differences concerning hibernation weight loss for larvae treated with the lectin GNA compared to the negative control for O. bicornis . Body size is related to the efficiency of food conversion by larvae and to general fitness of the adult bee (Bosch and Vicens 2006; Radmacher and Strohm 2010). Body size can also be used to control for differences within treatments as body size may affect emergence dates and survival rate during the winter (Beekman et al. 1998). Body size of the adult individuals can be measured using different metrics such as the anterior wing length (Bosch and Vicens 2002; Ohl and Thiele 2007). Wing length has been found to be affected by heavy metal pollution in $O$. bicornis, which makes it interesting to investigate effects of pesticides on body size (Szentgyörgyi et al. 2017). Another potential endpoint that can be measured is wing symmetry of individual bees. Fluctuating asymmetry in bilateral body structures of insects can be used to quantify the developmental stability and can have a direct effect on individual fitness resulting in negative effects on the population over time (Lens et al. 2002). Asymmetry can be induced by a wide range of environmental factors, including pesticides (Beasley et al. 2013). However, no data is available on the potential impact of pesticides on solitary bee wing symmetry (see Ondo et al. 2011; Gerard et al. 2018), leaving its potential use as an endpoint for risk assessment protocols for solitary bees subject to future research.

\section{TEST PROTOCOL}

Based on our own experiences and available larval toxicity protocols in literature (own unpublished data; Guirguis and Brindley 1974; Johansen et al. 1984; Peach et al. 1994; Tesoriero et al. 2003; Abbott et al. 2008; Konrad et al. 2008; Hodgson et al. 2011; Gradish et al. 2012; Sgolastra et al. 2015; Nicholls et al. 2017; Anderson and Harmon-Threatt 2019), we propose a test protocol for standardized oral toxicity tests for larvae of solitary bees of the genus Osmia spp. (summarized in Table II).

\subsection{Harvesting of the larvae}

Eggs and first instar larvae can be collected from artificial wooden laminar trap nests during the nesting activity of the adult females. We 
Table II. Recommendations for protocol elements for standardized oral toxicity tests for larvae of solitary bees of the genus Osmia spp.

Protocol elements

Test species

Larvae rearing method

Age of the larvae

Feeding method

Housing cage

Treatments

Replication

Application method

Exposure validation

Incubation
Recommendation

- O. cornuta (Europe)

- O. bicornis (Europe)

- O. cornifrons (USA and Japan)

- O. lignaria (USA and Canada)

- O. ribifloris (USA and Mexico)

Wooden laminar trap nest

Egg and first instar

New pollen method

Sterile 48-well plate

3 to 7 (1 negative control, 1 positive toxic control, and 1 to 5 concentrations of the test pesticide)

30 larvae

Mixing treatments with new pollen

Pesticide residues in untreated and treated pollen (the day of treatment and 28 days after treatment)

- Larval development: 120 days at $22{ }^{\circ} \mathrm{C}$ and $60 \% \mathrm{RH}$

- Prewintering: 21 days at $14{ }^{\circ} \mathrm{C}$ and $60 \% \mathrm{RH}$

- Wintering: 120 days at $4{ }^{\circ} \mathrm{C}$ and $60 \% \mathrm{RH}$

- Emergence: $22{ }^{\circ} \mathrm{C}$ and $60 \% \mathrm{RH}$

advise to gain experience when it comes to rearing in order to effectively harvest sufficient numbers of larvae for the test (but see Staab et al. 2018). Depending both on this experience and on the floral resources around the nesting site, it will depend how many females need to be released (own unpublished data; Pitts-Singer and Bosch 2010; Dainese et al. 2018). When working with multiple trap nests to harvest larvae, it is important to ensure that larvae from each trap nest are equally spread among treatments to minimize effects of confounding factors (but see Hendriksma et al. 2011). To ensure that larvae do not feed on the natural pollen provision, we propose that only the eggs and first instar larvae should be included in toxicity test to ascertain that all pollen-feeding larval stages consume only the experimental untreated or treated pollen. In addition, in order to develop a standardized toxicity test with the required sample size of one sex, female larvae should be selected (which is also in accordance with the honey bee and bumble bee test protocols: Dietemann et al. 2013; Cabrera et al. 2016; OECD 2017a, b). Male bees are also essential, of course, but priority should go to protocols targeting female bees due to the abovementioned reason and because they provide reproductive output and pollination services. Female larvae can be selected based on their size and based on the position in the trap nest. More specifically, female larvae have pollen provisions and brood cell that are noticeably larger than those of males and are usually positioned at the back of the nesting cavity (Raw 1972; Krunić and Stanisavljević 2006). The first instar larvae can be recognized as it remains in the egg and a spiracular line can be noticed, which allows the exchange of atmospheric gasses. The second instar hatches 6 to 8 days after the egg is laid and can be recognized as it is hatched completely from the egg and actively feeds on the pollen (Rust et al. 1989; Torchio 1989). We suggest to monitor the nesting activity in each nesting cavity and to harvest fresh eggs/first instars every 3 to 4 days to make sure that the harvested individuals are not older than the first instar. At this point, a first assessment of larval survival should be made (before transfer to the treatment pollen). Larvae that show signs of damage due to handling should be excluded from the final analysis. To ensure a sufficient number of 
individuals, additional eggs and first instar larvae can be included in the experiment to deal with sex uncertainty and potential losses due to damage during transfer (Hendriksma et al. 2011).

\subsection{Rearing method}

To mimic natural conditions as best as possible, the housing cage for the larvae should have dimensions similar to the natural nesting cavities. Round-bottomed glass vials or 48-well plates with a diameter of approximately $10 \mathrm{~mm}$ or similar have been found to be ideal (Becker and Keller 2015; Sgolastra et al. 2015). Using housing cages with a larger diameter can create problems for successful cocoon spinning (own unpublished data; Abbott et al. 2008; Figure 1).

In existing protocols, there is considerable variation concerning the method of feeding the larvae. Either the original maternal pollen provision from in the trap nest or a new artificial pollen provision made from honeybee-collected pollen can be provided to feed the larvae (the latter is referred to as "new pollen method" hereafter). When using pollen provided by the mother bee, this pollen is spiked with a certain pesticide dosage. However, with this method, natural variation in pollen composition may significantly impact

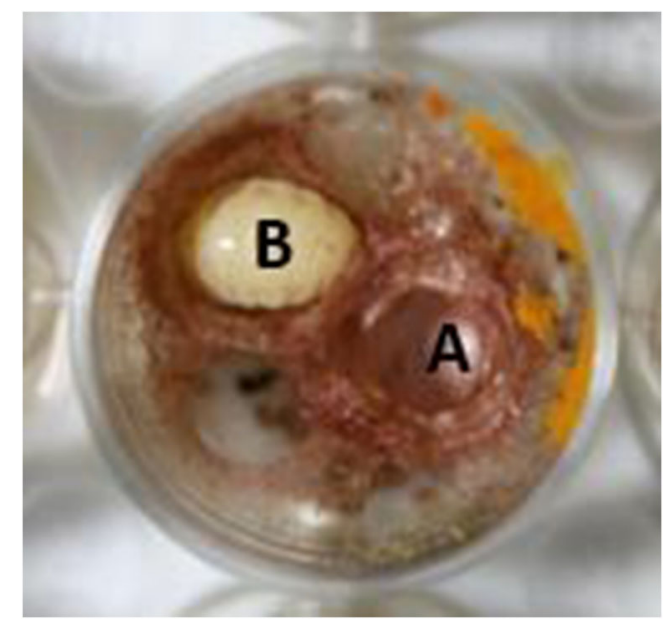

Figure 1 Hampered cocoon spinning caused by suboptimal housing cage $(15-\mathrm{mm}$-diameter well with flat bottom of 24-well plate) (A = first attempt to spin cocoon and $\mathrm{B}=$ second attempt to spin cocoon). offspring development (Guirguis and Brindley 1974; Bukovinszky et al. 2017). As it is hard to correct for this effect, we recommend the use of the new pollen method, allowing for a controlled provision of pollen to all larvae in the experiment. More specifically, it is possible to standardize the amount of pollen and the dosage of the test pesticide in the pollen, with a uniform mixing of the pesticide in the pollen provision also being more realistic compared to a spiked pollen provision. Undesired effects of pollen identity, microparasites, or pesticide residues in the honey bee pollen on larval mortality or development were previously found to be negligible (own unpublished data; Abbott et al. 2008; Konrad et al. 2008). Another advantage of using the new pollen method is that potential brood parasites or microparasites associated with the natural pollen provisions (e.g., Cacoxenus indigator, Apicystis spp.) cannot interfere with the experiment because they will not be transferred together with the larvae (own unpublished data; Becker and Keller 2015). Pollen provisions for each larva can be made by blending a batch of honey bee pollen and mixing this with $50 \%$ untreated or treated sugar water at a ratio 1:10 of sugar water and pollen (own unpublished data; Abbott et al. 2008; OECD 2017b). We suggest that all harvested eggs and first instar larvae should be provided with a pollen provision of $350 \mathrm{mg}$ (Bosch and Vicens 2002).

\subsection{Pesticide application}

Tier I toxicity tests should include a negative control, a positive validated toxic control, and one or more treatments of the test pesticide. For the positive control, dimethoate should be included next to the test compounds for larval toxicity tests in accordance with honey bee larvae toxicity test protocols (Hendriksma et al. 2011; Dietemann et al. 2013). However, the specific concentrations of this reference pesticide that cause effects on the suggested endpoints remain to be determined to serve as a suitable positive control for lethal and sublethal endpoints.

For pesticide application in the toxicity test, a stock solution needs to be made by diluting an amount of the test pesticide in $50 \% \mathrm{w} / \mathrm{v}$ sugar 
water. The treated sugar water is then diluted and mixed with the honey bee pollen at a 1:10 ratio. Different dilutions of the stock solution can be made in order to include different dosages of pesticide-treated pollen. If the technical grade product of the pesticide is used, the product is mixed with acetone and then added to the sugar water to improve solubility ( $5 \%$ acetone $\mathrm{v} / \mathrm{v}$; OECD 2017b). If this is the case, a solvent control treatment needs to be added in addition to the negative control treatment. Samples of untreated and treated pollen should be taken at least at the day of treatment and 28 days after treatment (Botias et al. 2015). These samples must be analyzed for residues of the test substance to quantify the effective exposure of the test pesticide in the different treatments. If possible, the samples should also be screened for residues of other pesticides to account for possible interaction effects between other pesticide residues and the different test treatments. Effects of the endpoints between the different treatments need to be compared by expressing the treatments on a pesticide concentration base as well as by expressing the treatments as the consumed dosage of the pesticide. To achieve the latter, effective consumption of pollen should be monitored for all larvae to accurately assess the consumed dose of pesticide for each larva throughout the experiment. Accurate measurement of pesticide residue consumption is necessary for the estimation of potential effects, while the amount of pollen consumed will affect the size of the adult bee (Radmacher and Strohm 2010; OECD 2017b) and thus needs to be taken into account when comparing body sizes between individuals.

\subsection{Incubation}

Eggs and larvae should be incubated for 120 days at $22{ }^{\circ} \mathrm{C}, 60 \% \mathrm{RH}$, and complete darkness to facilitate larval and pupal development (Bosch and Blas 1994; Bosch and Kemp 2003; Nicholls et al. 2017). To complete diapause and to stimulate emergence in the lab, cocoons should be subjected to a cold period. Optimal prewintering conditions have been found between 10 and 30 days at $14{ }^{\circ} \mathrm{C}$, and we therefore suggest a prewintering incubation of 21 days at $14{ }^{\circ} \mathrm{C}$ (Bosch et al. 2000; Bosch and Kemp 2004). Subsequently, the bees should be subjected to a wintering incubation for 120 days at $4{ }^{\circ} \mathrm{C}$ for optimal hibernation (Bosch and Blas 1994; Bosch and Kemp 2003, 2004). After wintering incubation, the cocoons in the 48-well plates-with the lid placed on top of the well plate to prevent emerging bees from escaping - need to be incubated at $22{ }^{\circ} \mathrm{C}, 60 \% \mathrm{RH}$, and complete darkness to stimulate emergence and checked daily to record endpoints. Upon emergence, adult bees can be kept in individual containers without food provision to assess their longevity in the absence of food.

\section{RESEARCH NEEDS}

\subsection{Positive toxic control}

As previously mentioned, a toxic reference pesticide is needed as positive toxic control for both lethal and sublethal endpoints on larval development. To date, most studies on solitary bee larvae only include a negative control (see references in Section 3). Determination of this toxic reference and its recommended concentration that will cause effects is needed for further validation of a standardized test protocol. We suggest using dimethoate as positive toxic reference pesticide in accordance with honey bee larval toxicity protocols (Hendriksma et al. 2011; Dietemann et al. 2013), as this will result in a more comprehensive and a more comparable test protocol. As previously mentioned, the specific concentrations of this test pesticide for both primary endpoints remain to be validated to serve as a suitable positive control.

\subsection{Female progeny}

The main goal is to protect pollination services and bee populations from negative effects following exposure to pesticides. In the case of solitary bees, the female bees build the nests and collect and provide the food provision for the larvae. In 
this way, females ensure the reproductive output of the population and are of prime importance of bee populations. Just as the focus is on female workers and queens in honey bee and bumble bee toxicity protocols (Dietemann et al. 2013; Cabrera et al. 2016; OECD 2017a, b), test protocols for solitary bees need to target female individuals. Therefore, more data on how to accurately identify females during the larval stage (e.g., based on the size of the brood cell and their position in the nesting cavity inside the trap nests) would reduce the likelihood of accidently rearing male individuals, which can only be assessed upon emergence, months after the treatment has been performed. Likewise, more data on the amount of pollen provision that is provided to female larvae in natural conditions would be beneficial for specific Osmia spp. test species, in order to improve the accuracy of lab condition experiments compared to realistic field conditions.

\subsection{Relevant pesticide treatments}

A variation of concentrations of different pesticides has been detected in pollen and nectar of wildflowers as well as pollen and nectar of crops (Botias et al. 2015; David et al. 2016; Wood and Goulson 2017). Thorough exposure assessments for solitary bees are needed to identify the present pesticides and to determine their residue concentration in the larvae's food provision (EFSA 2013). Therefore, residue analysis of pollen and nectar collected by mother bees or residue analyses of food provisions of larvae under field conditions in different landscapes could provide insight to which pesticides solitary bee larvae are subjected to. This will allow the identification and assessment of potential risks of relevant pesticides. In addition, the residue concentrations can then be used to test field realistic concentrations of relevant pesticides in higher tier testing.

\section{CONTRIBUTIONS}

ME, MP and GS conceived the study goal. All authors contributed to writing of the manuscript and approved the final manuscript.

\section{FUNDING INFORMATION}

The research was funded by the Research Foundation Flanders (FWO) PhD grants 1S71416N (ME) and $1 \mathrm{~S} 16917 \mathrm{~N}$ (MP). The authors also thank support by the Special Research Fund of Ghent University.

\section{COMPLIANCE WITH ETHICAL STANDARDS}

Conflict of interest The authors declare that they have no conflict of interest.

Recommandations concernant les protocoles d'essai normalisés de toxicité orale pour les larves d'abeilles solitaires, Osmia spp.

pesticides / abeilles solitaires / Osmia spp. / test de toxicité orale / écotoxicologie

Empfehlungen zu standardisierten Protokollen für orale Toxizitätstests bei Larven solitärer Bienen, Osmia spp.

pestizide / solitäre bienen / Osmia spp. / orale toxizitätstests / ökotoxikologie

\section{REFERENCES}

Abbott, V. A., Nadeau, J. L., Higo, H. A., \& Winston, M. L. (2008). Lethal and sublethal effects of imidacloprid on Osmia lignaria and clothianidin on Megachile rotundata (Hymenoptera: Megachilidae). J. Econ. Entomol., 101 (3), 784-796. https://doi.org/10.1603 /0022-0493(2008)101

Anderson, N. L., \& Harmon-Threatt, A. N. (2019). Chronic contact with realistic soil concentrations of imidacloprid affects the mass immature development speed, and adult longevity of solitary bees. Sci. Rep., 9 (3724), 1-9. https://doi.org/10.1038/s41598-01940031-9

Arena, M., \& Sgolastra, F. (2014). A meta-analysis comparing the sensitivity of bees to pesticides. Ecotoxicology, 23 (3), 324-334. https://doi.org/10.1007/s10646014-1190-1

Beasley, D. A. E., Bonisoli-alquati, A., \& Mousseau, T. A. (2013). The use of fluctuating asymmetry as a measure 
of environmentally induced developmental instability: A meta-analysis. Ecol. Indic., 30, 218-226. https://doi. org/10.1016/j.ecolind.2013.02.024

Becker, M.C. \& Keller, A. (2015) Laboratory rearing of solitary bees and wasps. Insect Sci., 23, 1-6. https://doi.org/10.1111/1744-7917.12242

Beekman, M., Stratum, P. Van, \& Lingeman, R. (1998). Diapause survival and post-diapause performance in bumblebee queens (Bombus terrestris ). Entomol. Exp. Appl., 89 (3), 207-214. https://doi.org/10.1046/j.15707458.1998.00401.x

Biddinger, D. J., Robertson, J. L., Mullin, C., Frazier, J., Ashcraft, S. A., Rajotte, E. G., ... Vaughn, M. (2013). Comparative toxicities and synergism of apple orchard pesticides to Apis mellifera (L.) and Osmia cornifrons (Radoszkowski). PLoS ONE, 8(9), e 72587. https://doi.org/10.1371/journal.pone.0072587

Biesmeijer, J. C., Roberts, S. P. M., Reemer, M., Ohlemuller, R., Edwards, M., Peeters, T., ... Kunin, W. E. (2006). Parallel declines in pollinators and insect-pollinated plants in Britain and the Netherlands. Science, 313, 351-354. https://doi.org/10.1126 /science. 1127863

Bosch, J., \& Blas, M. (1994). Effect of over-wintering and incubation temperatures on adult emergence in Osmia cornuta Latr (Hymenoptera, Megachilidae). Apidologie, 25(3), 265-277. https://doi.org/10.1051 /apido:19940301

Bosch, J. \& Kemp, W.P. (2000) Development and emergence of the orchard pollinator Osmia lignaria (Hymenoptera: Megachilidae). Environ. Entomol., 29, 813. https://doi.org/10.1603/0046-225x-29.1.8

Bosch, J., \& Kemp, W. P. (2003). Effect of wintering duration and temperature on survival and emergence time in males of the orchard pollinator Osmia lignaria (Hymenoptera: Megachilidae). Environ. Entomol., 32 (4), 711-716. https://doi.org/10.1603/0046-225X32.4.711

Bosch, J., \& Kemp, W. P. (2004). Effect of pre-wintering and wintering temperature regimes on weight loss, survival, and emergence time in the mason bee Osmia cornuta (Hymenoptera: Megachilidae). Apidologie, 35 (5), 469-479. https://doi.org/10.1051/apido

Bosch, J. \& Vicens, N. (2002). Body size as an estimator of production costs in a solitary bee. Ecol. Entomol. 27, 129-137.

Bosch, J., \& Vicens, N. (2006). Relationship between body size, provisioning rate, longevity and reproductive success in females of the solitary bee Osmia cornuta. Behav. Ecol. Sociobiol., 60 (1), 26-33. https://doi. org/10.1007/s00265-005-0134-4

Bosch, J., Kemp, W.P. \& Peterson, S.S. (2000) Management of Osmia lignaria (Hymenoptera: Megachilidae) populations for almond pollination: methods to advance bee emergence. Environ. Entomol., 29, 874883. https://doi.org/10.1603/0046-225x-29.5.874

Botias, C., David, A., Horwood, J., Abdul-sada, A., Nicholls, E., Hill, E., \& Goulson, D. (2015). Neonicotinoid residues in wild flowers, a potential route of chronic exposure for bees. Environ. Sci.
Technol., 49, 12731-12740. https://doi.org/10.1021 /acs.est.5b03459

Bukovinszky, T., Rikken, I., Evers, S., Wäckers, F.L., Biesmeijer, J.C., Prins, H.H.T., et al. (2017). Effects of pollen species composition on the foraging behaviour and offspring performance of the mason bee Osmia bicornis (L.). Basic Appl. Ecol., 18, 21-30. https://doi.org/10.1016/j.baae.2016.11.001

Cabrera, A. R., Almanza, T., Cutler, G. C., Fischer, D. L., Hinarejos, S., Lewis, G., ... Steen, J. Van Der. (2016). Initial recommendations for higher-tier risk assessment protocols for bumble bees, Bombus spp. (Hymenoptera: Apidae). Integr. Environ. Assess. Manag., 12 (2), 222-229. https://doi.org/10.1002/ieam.1675

Carvalheiro, L., Gigante, S., Kunin, W. E., Keil, P., Aguirre-Gutiérrez J. ... Biesmeijer, J. C. (2013). Species richness declines and biotic homogenization have slowed down for NW-European pollinators and plants. Ecol. Lett., 16(7), 870-878. https://doi.org/10.1111 /ele.12121

Dainese, M., Riedinger, V., Holzschuh, A., Kleijn, D., Scheper, J. \& Steffan-Dewenter, I. (2018) Managing trap-nesting bees as crop pollinators: Spatiotemporal effects of floral resources and antagonists. J. Appl. Ecol., 55, 195-204. https://doi.org/10.1111/13652664.12930

David, A., Botías, C., Abdul-sada, A., Nicholls, E., Rotheray, E. L., Hill, E. M., \& Goulson, D. (2016). Widespread contamination of wild flower and beecollected pollen with complex mixtures of neonicotinoids and fungicides commonly applied to crops. Environ. Int., 88, 169-178. https://doi. org/10.1016/j.envint.2015.12.011

Dietemann, V., Ellis, K. D., Neumann, P. (2013) The COLOSS BEEBOOK Volume I, Standard methods for Apis mellifera research. J. Apic. Res., $52: 4,1-4$, https://doi.org/10.3896/IBRA.1.52.4.23

EFSA (2013) Guidance on the risk assessment of plant protection products on bees (Apis mellifera, Bombus spp. and solitary bees). EFSA J. 11 .

Fauser, A., Sandrock, C., Neumann, P., \& Sadd, B. S. (2017). Neonicotinoids override a parasite exposure impact on hibernation success of a key bumblebee pollinator. Ecol. Entomol., 42 (3), 306-314. https://doi.org/10.1111/een.12385

Fogel, M. N., Ine, M., Ronco, A. E., \& Desneux, N. (2013). Impact of the neonicotinoid acetamiprid on immature stages of the predator Eriopis connexa (Coleoptera: Coccinellidae). Ecotoxicology, 22 (6), 1063-1071. https://doi.org/10.1007/s10646-013-1094-5

Forrest, J.R.K. \& Thomson, J. D. (2011) An examination of synchrony between insect emergence and flowering in Rocky Mountain meadows. Ecol. Monogr., 81 , 469491. https://doi.org/10.1890/10-1885.1

Garibaldi, L. A., Steffan-Dewenter, I., Winfree, R., Aizen, M. A., Bommarco, R., Cunningham, S. A., ... Klein, A. M. (2013). Wild pollinators enhance fruit set of crops regardless of honey bee abundance. Science, 339 (6127), 1608-1611. https://doi.org/10.1126 /science. 1230200 
Gerard, M., Michez, D., Debat, V., Fullgrabe, L., Meeus, I., Piot, N., Sculfort, O., Vastrade, M., Smagghe, G. \& Vanderplanck (2018). Stressful conditions reveal decrease in size, modification of shape but relatively stable asymmetry in bumblebee wings. Sci. Rep., 8, 15169. https://doi.org/10.1038/s41598-018-33429-4

Goulson, D., Nicholls, E., Botías, C., Rotheray, E.L., (2015). Bee declines driven by combined stress from parasites, pesticides, and lack of flowers. Science (80). 347, 1-16. https://doi.org/10.1126/science.1255957

Gradish, A. E., Scott-Dupree, C. D., Cutler, G. C. (2012). Susceptibility of Megachile rotundata to insecticides used in wild blueberry production in Atlantic Canada. J. Pest. Sci., 85(1), 133-140. https://doi.org/10.1007 /s10340-011-0391-0

Guirguis, G. N., \& Brindley, W. A. (1974). Insecticide susceptibility and response to selected pollens of larval alfalfa leafcutting bees, Megachile pacifica (Panzer) (Hymenoptera: Megachilidae). Environ. Entomol., 3 (4), 691-694. https://doi.org/10.1093/ee/3.4.691

Heard, M. S., Baas, J., Dorne, J.- Lou, Lahive, E., Robinson, A. G., Rortais, A., ... Hesketh, H. (2017). Comparative toxicity of pesticides and environmental contaminants in bees: Are honey bees a useful proxy for wild bee species? Sci. Total Environ., 578, 357-365. https://doi.org/10.1016/j.scitotenv.2016.10.180

Hendriksma, H. P., Härtel, P., \& Steffan-dewenter, I. (2011) Honey bee risk assessment: new approaches for in vitro larvae rearing and data analyses. Methods Ecol. Evol., 2, 509-517. https://doi.org/10.1111 /j.2041-210X.2011.00099.x

Hodgson, E. W., Pitts-singer, T. L., \& Barbour, J. D. (2011). Effects of the insect growth regulator, novaluron on immature alfalfa leafcutting bees, Megachile rotundata. J. Insect Sci., 11 (43), 1-10. https://doi. org/10.1673/031.011.0143

Huntzinger, I. C., James, R. R., Bosch, J., \& Kemp, W. P. (2008). Fungicide tests on adult alfalfa leafcutting bees (Hymenoptera: Megachilidae). J. Econ. Entomol., 101 (4), 1088-1094. https://doi.org/10.1603/00220493(2008)101

Jin, N., Klein, S., Leimig, F., Bischoff, G., \& Menzel, R. (2015). The neonicotinoid clothianidin interferes with navigation of the solitary bee Osmia cornuta in a laboratory test. J. Exp. Biol., 218(18), 2821-2825. https://doi.org/10.1242/jeb.123612

Johansen, C. A., Rincker, C. M., George, D. A., Mayer, D. F., \& Kious, A. W. (1984). Effects of aldicarb and its biologically active metabolites on bees. Environ. Entomol., 13 (5), 1386-1398. https://doi.org/10.1093 /ee/13.5.1386

Kemp, W. P., Bosch, J., \& Dennis, D. (2004). Oxygen consumption during the life cycles of the prepupawintering bee Megachile rotundata and the adultwintering bee Osmia lignaria (Hymenoptera: Megachilidae), Ann. Entomol. Soc. Am., 97 (1), 161170. https://doi.org/10.1603/0013-8746(2004)097 [0161:OCDTLC]2.0.CO;2

Konrad, R., Ferry, N., Gatehouse, A. M. R., \& Babendreier, D. (2008). Potential effects of oilseed rape expressing oryzacystatin-1 (OC-1) and of purified insecticidal proteins on larvae of the solitary bee Osmia bicornis . PLoS ONE, 3 (7), e2664. https://doi.org/10.1371/journal.pone. 0002664

Kopit, A. M., \& Pitts-singer, T. L. (2018). Routes of pesticide exposure in solitary, cavity-nesting bees. Environ. Entomol., 47 (3), 499-510. https://doi.org/10.1093 /ee/nvy034

Krunić, M.D., Stanisavljević, L.Z., (2006). The biology of European orchard Bee Osmia cornuta (Latr.) (Hymenoptera: Megachilidae). Belgrade: University of Belgrade.

Ladurner, E., Bosch, J., Kemp, W. P., \& Maini, S. (2005). Original article asessing delayed and acute toxicity of five formulated fungicides to Osmia lignaria Say and Apis mellifera. Apidologie, 36 (3), 449-460. https://doi.org/10.1051/apido

Lens, L., Dongen, S. Van, Kark, S. \& Matthysen, E. (2002) Fluctuating asymmetry as an indicator of fitness: Can we bridge the gap between studies? Biol. Rev., 77, 2738. https://doi.org/10.1017/S1464793101005796

Michener, C. D., (2007). The nees of the world. Baltimore: The Johns Hopkins University Press.

Nicholls, E., Fowler, R., Niven, J. E., Gilbert, J. D., \& Goulson, D. (2017). Larval exposure to field-realistic concentrations of clothianidin has no effect on development rate, over-winter survival or adult metabolic rate in a solitary bee, Osmia bicornis . PeerJ, e3417. https://doi.org/10.7717/peerj.3417

Norden, B. B. (1984). Nesting biology of Anthophora abrupta (Hymenoptera: Anthophoridae). J. Kansas Entomol. Soc., 57 (2), 243-262.

OECD (2017a), Test No. 246: Bumblebee, acute contact toxicity test, OECD guidelines for the testing of chemicals, Section 2, OECD Publishing, Paris, https://doi.org/10.1787/9789264284104-en

OECD (2017b), Test No. 247: Bumblebee, acute oral toxicity test, OECD guidelines for the testing of chemicals, Section 2, OECD Publishing, Paris, https://doi.org/10.1787/9789264284128-en

Ohl, M., \& Thiele, K. (2007). Estimating body size in apoid wasps: the significance of linear variables in a morphologically diverse taxon (Hymenoptera, Apoidea). Zoosystemat. Evol., 83 (2), 110-124. https://doi. org/10.1002/mmnz.200700003

Ollerton, J., Winfree, R., Tarrant, S., (2011). How many flowering plants are pollinated by animals? Oikos $\mathbf{1 2 0}$, 321-326. https://doi.org/10.1111/j.16000706.2010.18644.x

Ondo, N. A. Z., Alibert, P., Dousset, S., Savadogo, P. W., Savadogo, M., \& Sedogo, M. (2011). Chemosphere insecticide residues in cotton soils of Burkina Faso and effects of insecticides on fluctuating asymmetry in honey bees (Apis mellifera Linnaeus). Chemosphere, 83 (4), 585-592. https://doi.org/10.1016/j. chemosphere.2010.12.021

Peach, M. L., Alston, D. G., Tepedino, V. J. (1994). Bees and bran bait: is carbaryl bran bait lethal to alfalfa leafcutting Bbee (Hymenoptera: Megachilidae) adults 
or larvae? J. Econ. Entomol., 87 (2), 311-317. https://doi.org/10.1093/jee/87.2.311

Pitts-Singer, T.L. \& Bosch, J. (2010) Nest establishment, pollination efficiency, and reproductive success of Megachile rotundata (Hymenoptera: Megachilidae) in relation to resource availability in field enclosures. Environ. Entomol., 39, 149-158. https://doi. org/10.1603/en09077

Powney, G.D., Carvell, C., Edwards, M., Morris, R.K.A., Roy, H.E., Woodcock, B.A., Isaac, N.J.B., (2019). Widespread losses of pollinating insects in Britain. Nat. Commun. 10, 1018. https://doi.org/10.1038 /s41467-019-08974-9

Radmacher, S., \& Strohm, E. (2010). Factors affecting offspring body size in the solitary bee Osmia bicornis (Hymenoptera, Megachilidae). Apidologie, 41 (2), 169-177. https://doi.org/10.1051/apido/2009064

Raw, A. (1972) The biology of the solitary bee Osmia rufa (L.) (Megachilidae). Trans. R. Entomol. Soc. Lond., 124, 213-229. https://doi.org/10.1111/j.13652311.1972.tb00364.x

Rust, R., Torchio, P., \& Trostle, R. (1989). Late embryogenesis and immature development of Osmia rufa cornigera (Rossi) (Hymenoptera: Megachilidae). Apidologie, 20 (4), 359-367. https://doi.org/10.1051 /apido: 19890408

Sandrock, C., Tanadini, L.G., Pettis, J.S., Biesmeijer, J.C., Potts, S.G. \& Neumann, P. (2014) Sublethal neonicotinoid insecticide exposure reduces solitary bee reproductive success. Agric. For. Entomol., 16, 119-128. https://doi.org/10.1111/afe.12041

Schenk, M., Krauss, J., \& Holzschuh, A. (2018a). Desynchronizations in bee-plant interactions cause severe fitness losses in solitary bees. J. Anim. Ecol., 87 (1), 139-149. https://doi.org/10.1111/13652656.12694

Schenk, M., Mitesser, O., Hovestadt, T., \& Holzschuh, A. (2018b). Overwintering temperature and body condition shift emergence dates of spring-emerging solitary bees. PeerJ, 6, e4721. https://doi.org/10.7717 /peerj.4721

Scott-dupree, C. D., Conroy, L., \& Harris, C. R. (2009). Impact of currently used or potentially useful insecticides for canola agroecosystems on Bombus impatiens (Hymenoptera: Apidae), Megachile rotundata (Hymentoptera: Megachilidae), and Osmia lignaria (Hymenoptera: Megachilidae). J. Econ. Entomol., 102 (1), 177-182. https://doi.org/10.1603 /029.102.0125

Sgolastra, F., Kemp, W.P., Buckner, J.S., Pitts-Singer, T.L., Maini, S. \& Bosch, J. (2011) The long summer: prewintering temperatures affect metabolic expenditure and winter survival in a solitary bee. J. Insect Physiol., 57, 1651-1659. https://doi.org/10.1016/j. jinsphys.2011.08.017

Sgolastra, F., Tosi, S., Medrzycki, P., Porrini, C., \& Burgio, G. (2015). Toxicity of spirotetramat on solitary bee larvae, Osmia cornuta (Hymenoptera: Megachilidae), in laboratory conditions. J. Apicult. Sci., 59 (2), 73-83. https://doi.org/10.1515/JAS-2015-0024
Sgolastra, F., Medrzycki, P., Bortolotti, L., Renzi, T., Tosi, S., Bogo, G., ... Bosch, J. (2017). Synergistic mortality between a neonicotinoid insecticide and an ergosterolbiosynthesis-inhibiting fungicide in three bee species. Pest Manag. Sci., 73 (6), 1236-1243. https://doi. org/10.1002/ps.4449

Sgolastra, F., Hinarejos, S., Pitts-singer, T. L., Boyle, N. K., Joseph, T., Johannes, L., ... Bosch, J. (2018a). Pesticide exposure assessment paradigm for solitary bees. Environ. Entomol., nvy105, 1-14. https://doi. org/10.1093/ee/nvy105

Sgolastra, F., Arnan, X., Cabbri, R., Isani, G., Medrzycki, P., Teper, D., \& Bosch, J. (2018b). Combined exposure to sublethal concentrations of an insecticide and a fungicide affect feeding, ovary development and longevity in a solitary bee. Proc. R. Soc. B Biol. Sci., 285, 20180887. https://doi.org/10.1098/rspb.2018.0887

Staab, M., Pufal, G., Tscharntke, T. \& Klein, A.M. (2018) Trap nests for bees and wasps to analyse trophic interactions in changing environments - A systematic overview and user guide. Methods Ecol. Evol., 9, 22262239. https://doi.org/10.1111/2041-210X.13070

Stoner, K. A. (2016). Current pesticide risk assessment protocols do not adequately address differences between honey bees (Apis mellifera) and bumble bees (Bombus spp.). Front. Environ. Sci., 4 (December), 18. https://doi.org/10.3389/fenvs.2016.00079

Straub, L., Williams, G. R., Pettis, J., Fries, I., \& Neumann, P. (2015). Superorganism resilience: eusociality and susceptibility of ecosystem service providing insects to stressors. Curr. Opin. Insect Sci. 12, 109-112. https://doi.org/10.1016/j.cois.2015.10.010

Szentgyörgyi, H., Moron, D., Nawrocka, A., Tofilski, A., \& Woyciechowski, M. (2017). Forewing structure of the solitary bee Osmia bicornis developing on heavy metal pollution gradient. Ecotoxicology, 26(8), 10311040. https://doi.org/10.1007/s10646-017-1831-2

Tesoriero, D., Maccagnani, B., Santi, F., \& Celli, G. (2003). Toxicity of three pesticides on larval instars of Osmia cornuta: preliminary results. Bull. Insectol., 56(1), 169-171.

Thompson, H. (2016). Extrapolation of acute toxicity across bee species. Integr. Environ. Assess. Manag., 12 (4), 622-626. https://doi.org/10.1002/ieam.1737

Thompson, H., Pamminger, T. (2019). Perspective: Are honeybees suitable surrogates for use in pesticide risk assessment for non-Apis bees? Pest Manag. Sci., accepted online. https://doi.org/10.1002/ps.5494

Torchio, P. F. (1989). In-nest biologies and development of immature stages of three Osmia species (Hymenoptera: Megachilidae). Ann. Entomol. Soc. Am., 82 (5), 599-615. https://doi.org/10.1093/aesa/82.5.599

Uhl, P., Franke, L. A., Re, C., Wollmann, C., Peter, S., Jeker, L., \& Brühl, C. A. (2016). Interspecific sensitivity of bees towards dimethoate and implications for environmental risk assessment. Sci. Rep., 6(34439), 1-7. https://doi.org/10.1038/srep34439

Vázquez, D.E., Ilina, N., Pagano, E.A., Zavala, J.A., Farina, W.M., 2018. Glyphosate affects the larval development of honey bees depending on the susceptibility of 
colonies. PLoS One 13, e0205074. https://doi. org/10.1371/journal.pone.0205074

Weissel, N., Mitesser, O., Poethke, H.J. \& Strohm, E. (2012) Availability and depletion of fat reserves in Halictid foundress queens with a focus on solitary nest founding. Insect. Soc., 59, 67-74. https://doi. org/10.1007/s00040-011-0189-3

Wood, T. J., \& Goulson, D. (2017). The environmental risks of neonicotinoid pesticides: a review of the evidence post 2013. Environ. Sci. Pollut. Res., 24(21), 17285-17325. https://doi.org/10.1007/s11356-0179240-x

Woodcock, B. A., Bullock, J. M., Shore, R. F., Heard, M. S., Pereira, M. G., Redhead, J., ... Pywell, R. F. (2017). Country-specific effects of neonicotinoid pesticides on honey bees and wild bees. Science, 356 (6345), 13931395. https://doi.org/10.1126/science.aaa1190
Wu, J.Y., Anelli, C.M., Sheppard, W.S., (2011). Sub-lethal effects of pesticide residues in brood comb on worker honey bee (Apis mellifera) development and longevity. PLoS One 6, e14720. https://doi.org/10.1371/journal.pone. 0014720

Youn, Y. N., Seo, M. J., Shin, J. G., Jang, C., \& Yu, Y. M. (2003). Toxicity of greenhouse pesticides to multicolored Asian lady beetles, Harmonia axyridis (Coleoptera: Coccinellidae). Biol. Control, 28(2), 164-170. https://doi.org/10.1016/S1049-9644(03)00098-7

Publisher's note Springer Nature remains neutral with regard to jurisdictional claims in published maps and institutional affiliations. 